\title{
EDS quantification of light elements using osmium surface coating
}

\author{
Hiroaki OHFUנI and Masashi YАмАмото \\ Geodynamics Research Center, Ehime University, Matsuyama, Ehime 790-8577, Japan
}

\begin{abstract}
This study demonstrates the validity of a thin osmium coating for quantitative energy-dispersive spectroscopic (EDS) analysis, particularly for light elements such as $\mathrm{O}$ (and potentially $\mathrm{C}$ and $\mathrm{N}$ ) in natural/synthetic minerals . An osmium coating prepared by chemical vapor deposition provides an extremely thin and uniform layer whose thickness can be controlled simply by coating time. Because of the high reproducibility and reliability of the osmium coating process, users have no difficulty in evaluating the actual coating thickness, which enables strict and precise absorption corrections (for the coating layer), even for low-energy characteristic X-rays, which are susceptible to attenuation by the coating layer itself. Our results show that oxygen concentrations in silicate and oxide minerals can be quantified correctly when using the osmium coating, whereas quantification using a carbon coating afforded values that were a few wt $\%$ lower than stoichiometry, probably due to the uncertainty of the actual coating thickness (i.e., the absorption correction was incorrect). The ability to accurately quantify oxygen may stimulate new analytical applications, such as the estimation of $\mathrm{Fe}^{2+} / \mathrm{Fe}^{3+}$ concentrations and water content in minerals. Furthermore, the Os-coated samples prepared for EDS analysis are also suitable for electron back-scattered diffraction (EBSD) analysis without re-polishing and re-coating, which are usually routine but time-consuming tasks in the case of carbon-coated samples.
\end{abstract}

Keywords: Electron probe microanalysis (EPMA), Osmium coating, EDS, Quantification

\section{INTRODUCTION}

Electron probe microanalysis (EPMA) is a non-destructive method that is widely used to investigate the chemical compositions of solid materials, including not only minerals and rocks, but also industrial and biological materials. Recent advances in solid-state X-ray detectors for energy dispersive spectroscopic (EDS) analysis have allowed the ready collection of precise quantitative data. For the SEM observation and EDS analysis of non-conductive (insulating) materials such as most minerals and rocks, surface coating with a thin conductive layer is a prerequisite for sample preparation. Carbon, with its low atomic number, is most commonly used for quantitative analysis because of its low attenuation of the characteristic X-rays emitted from a bombarded target (sample). Gold and platinum are also frequently used for surface coating, especially in samples with rough, uneven surfaces and/or high porosity, but are usually not suitable for quantitative analysis due to their high attenuation characteristics.

doi:10.2465/jmps. 141126

H. Ohfuji, ohfuji@ sci.ehime-u.ac.jp Corresponding author
Another alternative is an osmium coating, as prepared by the low-voltage discharge chemical vapor deposition (CVD) method (Tanaka, 1994; Akahori et al., 2000). This can provide a significantly thin conductive coating of down to $<1 \mathrm{~nm}$ (although usually, a few to several nm thick) composed of extremely fine amorphous particles that are virtually invisible and do not obscure the fine surface structure of specimens at very high-magnification observation. Therefore, thin osmium coatings have been used preferentially for the SEM imaging of biological textures such as found in cells, tissues, and membranes (e.g., Osawa and Nozaka, 1998; Akahori et al., 2000; Suzuki, 2002). The extreme thinness of the osmium coating may also be favorable for chemical quantitative analysis via electron microprobe, although the $\mathrm{Z}$ number of osmium is as large as those of gold and platinum (i.e., high X-ray attenuation). In fact, several pioneering studies on EPMA quantitative analysis have been conducted using ultra-thin conductive coatings prepared from gold (Willich and Obertop, 1990; Jercinovic and Williams, 2005), copper (Love et al., 1974; Weisweiler, 1974), and nickel (Bizouard and Charpentier, 1979) by wavelength dispersive spectroscopy (WDS). Some of these studies particularly focused on the quantification 
of light elements such as oxygen through the accurate evaluation of the mass absorption of X-rays by the coating layer. For instance, Love et al. (1974) used a thin $(<10 \mathrm{~nm})$ layer of copper for the surface coating of oxides such as $\mathrm{MgO}, \mathrm{Cr}_{2} \mathrm{O}_{3}$, and $\mathrm{Fe}_{2} \mathrm{O}_{3}$ and found that the results support the thin-film model proposed for the quantitative analysis of light elements (Duncumb and Melford, 1966). Jercinovic and Williams (2005) tested a thin $(10 \mathrm{~nm})$ gold coating in the analysis of monazite. They found it usable for accurate quantification and very effective in reducing the surface damage caused by a large-current $(200 \mathrm{nA}, 15 \mathrm{kV})$ electron beam because of its high thermal conductivity. On the other hand, a Monte Carlo simulation by Kato (2007) suggested that even a $10 \mathrm{~nm}$ gold coating influences the accuracy of the quantification, because it distorts the depth distribution of the generated X-rays, giving, for example, a higher $K$-ratio for the Th $\mathrm{M} \alpha$ line between the sample (monazite) and standard (pure thorium) than the case of a 25 $\mathrm{nm}$ carbon coating. This means that the choice of conductive coating materials could influence the accuracy of quantification results in some cases (depending on the sample).

In the present study, we tested an extremely thin osmium coating $(5 \mathrm{~nm})$ for the EDS quantification of a variety of mineral samples. The results showed that it is not only applicable for the normal quantification of major oxide and silicate minerals, but also effective for the accurate quantification of light elements such as $\mathrm{O}$ (and potentially $\mathrm{C}$ and $\mathrm{N}$ ).

\section{EXPERIMENTAL}

The mineral samples (major rock-forming oxides and silicates, including hydrous species) analyzed in this study were all prepared by polishing with 6,3 , and finally $1 \mu \mathrm{m}$ diamond pastes on a rotating wheel. They were then coated with a very thin osmium layer deposited by the CVD method using a consumer-friendly osmium coater (NeocSTB), which is commercially available from Meiwafosis Co. Ltd (Japan). This coater is equipped to safely remove the residual toxic $\mathrm{OsO}_{4}$ gas that fills the vacuum chamber during coating by glow discharge. The details of the coating mechanism as well as the functions and specifications of the facility can be found at the supplier's website (http://www.meiwafosis.com/products/neoc/neoc_tokucho. $\mathrm{html}$ ). According to the website, the thickness of the coating layer can be controlled by simple adjustment of the coating time at a fixed discharge current of $10 \mathrm{~mA}$ and a constant vacuum level of $7 \mathrm{~Pa}$. The thickness was determined directly by the TEM observation of cross-sections of small plastic blocks with osmium surface coatings. In the present study, a coating thickness of $5 \mathrm{~nm}$ (produced by a coating time of $10 \mathrm{~s}$ ) was used for all the samples. For comparative purposes, several samples were coated with a thin carbon layer by using an automatic carbon coater (JEOL, JEC-560). The thickness of the carbon coating layer was estimated as $15-20 \mathrm{~nm}$ from the surface color change of a glass slide, and was crosschecked using the color change of a white tile with an oil drop (using a thickness reference kit purchased from JEOL).

Quantitative analysis was performed with a fieldemission scanning electron microscope (FE-SEM; JEOL, JSM-7000F) equipped with EDS detectors. Data were obtained with a solid-state detector (SSD; Oxford Instruments, INCA E250) as well as a silicon drift detector (SDD; Oxford Instruments, X-Max 20). The software used for the data analysis were INCA ver. 4.06 for the former system and AZtec ver. 2.1 for the latter, both of which employed the XPP matrix correction algorithm (Pouchou and Pichoir, 1991) for quantitative calculations. The analytical conditions were $15 \mathrm{kV}, 0.53 \mathrm{nA}$, and a $50 \mathrm{~s}$ acquisition time for the former and $15 \mathrm{kV}, 1.0 \mathrm{nA}$, and $20 \mathrm{~s}$ for the latter. The analyzer software packages (INCA and AZtec) are also equipped with a standard function for correcting X-ray absorption by the surface coating layer, in which we simply choose the coating material (element) and the thickness.

\section{RESULTS AND DISCUSSION}

Initially, we analyzed several natural silicate and oxide minerals after coating with osmium and compared the quantification results with those obtained after coating the same samples with carbon. No significant differences in the quantification values (calculated in the oxide form) or the standard errors were found, suggesting that a thin ( $5 \mathrm{~nm}$ ) osmium surface coating is suitable for ordinary quantification. The same datasets were then used to calculate the individual element contents (including oxygen, quantified as a separate element).

Tables 1 and 2 present the quantification results for corundum and forsterite (commercial EPMA standards,

Table 1. Quantification results for corundum, $\mathrm{Al}_{2} \mathrm{O}_{3}$, with $\mathrm{C}$ and Os coatings

\begin{tabular}{ccrr}
\hline Element & C coating & Os coating & Stoichiometry \\
\hline $\mathrm{Al}$ & $52.66(12)$ & $52.74(10)$ & 52.93 \\
$\mathrm{O}$ & $44.94(17)$ & $47.47(25)$ & 47.07 \\
\hline Total & $97.60(17)$ & $100.21(28)$ & 100.00 \\
\hline
\end{tabular}

Calibration standards: $\mathrm{Al}, \mathrm{Al}_{2} \mathrm{O}_{3} ; \mathrm{O}, \mathrm{SiO}_{2}$. 
Table 2. Quantification results for forsterite, $(\mathrm{Mg}, \mathrm{Fe})_{2} \mathrm{SiO}_{4}$, with $\mathrm{C}$ and Os coatings

\begin{tabular}{crrr}
\hline Element & \multicolumn{1}{c}{ C coating } & \multicolumn{1}{c}{ Os coating } & ${ }^{*}$ Reference \\
\hline $\mathrm{Si}$ & $19.04(16)$ & $19.42(9)$ & 18.63 \\
$\mathrm{Mg}$ & $30.86(12)$ & $30.35(14)$ & 30.65 \\
$\mathrm{Fe}$ & $6.81(18)$ & $6.87(25)$ & 6.82 \\
$\mathrm{O}$ & $41.66(29)$ & $43.60(29)$ & 43.35 \\
\hline Total & $98.37(28)$ & $100.24(24)$ & 99.45 \\
\hline
\end{tabular}

Calibration standards: $\mathrm{Si}, \mathrm{SiO}_{2} ; \mathrm{Mg}, \mathrm{Mg}_{2} \mathrm{SiO}_{4} ; \mathrm{Fe}, \mathrm{Fe}_{2} \mathrm{SiO}_{4} ; \mathrm{O}$, $\mathrm{SiO}_{2}$.

${ }^{*}$ Reference values were the result of WDS analysis published by JEOL, from which the sample was purchased.

JEOL), respectively. The oxygen concentrations obtained from the osmium-coated samples were close to the stoichiometric values (published by JEOL), whereas both results from the carbon-coated ones were approximately 2 $\mathrm{wt} \%$ lower. The concentrations of other elements (cations) were nearly equivalent to the stoichiometric values, and no differences were found between the osmium- and carbon-coated samples. The deviations in the oxygen concentrations of the carbon-coated samples are likely derived from the uncertainty of the thickness of the coating. We assumed the thickness of the carbon coating to be $15-20 \mathrm{~nm}$ from the color change (to very faint brown) of the glass slide on which the samples were placed during coating. We also used a piece of white tile with an oil drop to double-check the thickness via color change. These are the most common and practical ways to readily estimate the thickness of carbon coatings deposited on samples. However, estimation by these methods can generate error to a greater or lesser extent. Figure 1a shows the relationship between the thickness of the surface coatings ( $\mathrm{C}$ and $\mathrm{Os})$ and the attenuation of the oxygen $\mathrm{K \alpha} \mathrm{X}-$ ray $(E=0.525 \mathrm{keV})$, calculated using the X-ray absorption coefficient of each element (Chantler, 1995). The attenuation of the X-ray by a $5 \mathrm{~nm}$ osmium layer (used in this study) is estimated to be approximately $11 \%$, which is larger than that by a $15-20 \mathrm{~nm}$ carbon layer (4-6\%). In an actual quantification experiment, this attenuation by the surface coating can be corrected, if the correct thickness value is provided to the software. However, in reality, many SEM-EDS users (unlike WDS users) do not pay special attention to controlling the carbon coating thickness, and often use a fixed (or default) value for the thickness correction when using the quantification software. The deviation from the actual coating thickness could cause non-negligible uncertainty in the attenuation correction of the coating layer (Fig. 1a). Figure 1b shows
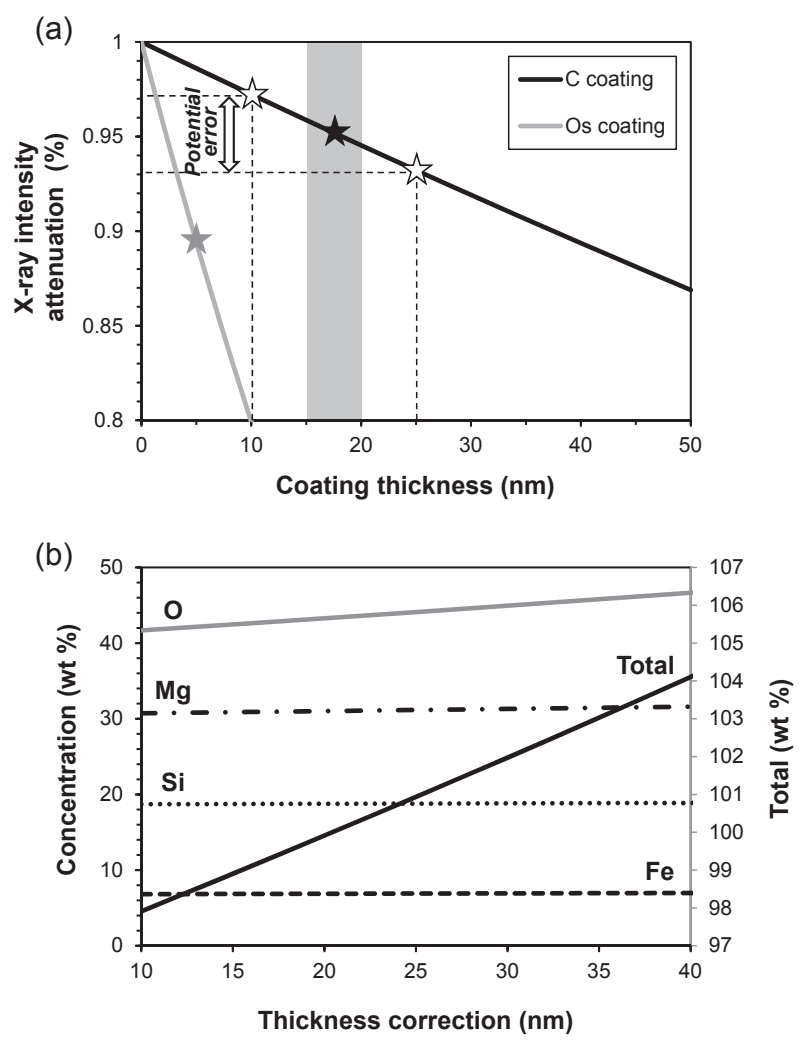

Figure 1. (a) Attenuation rates of $\mathrm{X}$-ray $(\mathrm{O} K \alpha)$ intensity vs. thickness of surface coatings ( $\mathrm{C}$ and $\mathrm{Os}$ ). The filled star and greyshaded range indicate the thickness of the carbon coating prepared in this study and its potential error, respectively. The range between the two open stars shows the possible uncertainty in the coating thickness which could occur in general sample preparation for SEM-EDS analysis. (b) Influence of the correction of the carbon coating thickness on the quantification results. Quantification calculations were made using various thickness correction values in INCA software (Oxford Instruments).

the variation in the quantitative values for each element and their total sum (obtained from forsterite, shown in Table 2) when changing the coating thickness value used for the attenuation correction in the quantification software. The total sum varies from $\sim 98$ to $\sim 104 \%$ upon changing the thickness correction value from 10 to 40 $\mathrm{nm}$, which is mostly attributed to the variation in the quantitative values for oxygen (Fig. 1b). This is simply due to the relatively larger attenuation of the characteristic X-ray of oxygen (Bastin and Heijligers, 1991), whose energy is lower than those of the other elements, by the surface coating layer. For example, an under/overestimation of $\pm 5 \mathrm{~nm}$ for the thickness of the carbon coating yields an uncertainty of $\sim 1.7 \%$ in the quantified oxygen concentration. The slightly lower oxygen concentrations, as compared to the reference values, obtained from the carbon-coated samples may be attributed to the uncertainty of the actual coating thickness. On the other hand, 
Table 3. Quantification results for magnetite, $\mathrm{Fe}_{3} \mathrm{O}_{4}$, with Os coating

\begin{tabular}{ccccccrr}
\hline \multirow{2}{*}{ Element } & \multicolumn{2}{c}{ Weight\% } & \multicolumn{2}{c}{ Atomic\% } & Element & \multicolumn{2}{c}{ Atomic\% } \\
& Observed & Expected & Observed & Expected & & Estimated & Stoichiometry \\
\hline \multirow{2}{*}{$\Sigma \mathrm{Fe}$} & $71.47(58)$ & 72.36 & $42.65(35)$ & 42.86 & $\mathrm{Fe}^{2+}$ & $13.25(5)$ & 14.29 \\
$\mathrm{O}$ & $27.53(24)$ & 27.64 & $57.35(50)$ & 57.14 & $\mathrm{~F}$ & $57.35(50)$ & 57.14 \\
\hline Total & $99.00(71)$ & 100.00 & 100.00 & 100.00 & Total & 100.00 & 100.00 \\
\hline
\end{tabular}

Calibration standards: $\mathrm{Fe}, \mathrm{Fe}_{2} \mathrm{SiO}_{4} ; \mathrm{O}, \mathrm{SiO}_{2}$.

since the thickness of the osmium coating can be precisely controlled by coating time at a given discharge current and pressure, the X-ray attenuation by the thin coating layer can be correctly evaluated, enabling accurate oxygen quantification. In pioneering studies that focused on the quantification of light elements, attempts were also made to control and evaluate the thickness of the surface coating for accurate attenuation correction. For example, Love et al. (1974) and Weisweiler (1974) used a copper coating and measured the $\mathrm{CuK \alpha}$ intensity to estimate the coating thickness, and Bizouard and Charpentier (1979) and Willich and Obertop (1990) used thin coatings of nickel and gold, respectively. A clear advantage of the present osmium coating is that it is not necessary to evaluate the coating thickness every time because of the high reproducibility and reliability of the plasma CVD coating process. For carbon coating, the thickness uncertainty can also be reduced by using high-vacuum carbon coaters equipped with a diffusion pump or turbo molecular pump in addition to a rotary pump. Then, the accurate quantification of oxygen would be expected.

The ability to accurately quantify oxygen when using osmium coatings opens up new applications for the chemical analysis of compounds. Table 3 shows the quantification results for magnetite, $\mathrm{Fe}_{3} \mathrm{O}_{4}$, in which the $\mathrm{Fe}$ and $\mathrm{O}$ concentrations were calculated separately from each $\mathrm{X}$-ray intensity. Note that the concentration of $\mathrm{Fe}^{2+}$ $(\mathrm{X})$ and $\mathrm{Fe}^{3+}(\mathrm{Y})$ can simply be estimated from the measured $\mathrm{Fe}$ and $\mathrm{O}$ values by the equations: $\mathrm{X}+\mathrm{Y}=42.65$ (atm $\%$, total $\mathrm{Fe}(\Sigma \mathrm{Fe})$ concentration), and $\mathrm{X}+3 / 2 \mathrm{Y}=$ 57.35 (atm $\%$, oxygen concentration). The obtained values $\left(\mathrm{Fe}^{2+}: 13.25 \mathrm{~atm} \%, \mathrm{Fe}^{3+}: 29.40 \mathrm{~atm} \%\right)$ are nearly consistent with the stoichiometric values $\left(\mathrm{Fe}^{2+}: 14.29\right.$ atm $\%, \mathrm{Fe}^{3+}: 28.57 \mathrm{~atm} \%$ ). The subtle differences are likely due to the slightly lower-than-stoichiometric $\Sigma \mathrm{Fe}$ value $(71.47 \mathrm{wt} \%)$. The lower $\Sigma \mathrm{Fe}$ value decreases the $\mathrm{Fe} / \mathrm{O}$ atomic ratio, which eventually increases the $\mathrm{Fe}^{3+}$ concentration, since 1.5 times more oxygen is allocated for $\mathrm{Fe}^{3+}$ than for $\mathrm{Fe}^{2+}$ when forming oxides (i.e., $\mathrm{Fe}_{2} \mathrm{O}_{3}$ and $\mathrm{FeO}$ ).
Table 4. Quantification results for antigorite, $\left(\mathrm{Mg}, \mathrm{Fe}, \mathrm{Al}_{6}\right)_{6} \mathrm{Si}_{4} \mathrm{O}_{10}$ $(\mathrm{OH})_{8}$

\begin{tabular}{|c|c|c|}
\hline Element & $w t \%$ & Stoichiometry \\
\hline $\mathrm{Si}$ & $20.16(17)$ & 20.27 \\
\hline $\mathrm{Mg}$ & $23.23(29)$ & \\
\hline $\mathrm{Fe}$ & $2.47(15)$ & 26.31 \\
\hline $\mathrm{Al}$ & $0.84(7)$ & \\
\hline $\mathrm{O}$ & $51.92(59)$ & 51.96 \\
\hline $\mathrm{H}$ & -1.38 & 1.45 \\
\hline Total & $98.62(94)$ & 100.00 \\
\hline
\end{tabular}

Calibration standards: $\mathrm{Si}, \mathrm{SiO}_{2} ; \mathrm{Mg}, \mathrm{Mg}_{2} \mathrm{SiO}_{4} ; \mathrm{Fe}, \mathrm{Fe}_{2} \mathrm{SiO}_{4} ; \mathrm{Al}$, $\mathrm{Al}_{2} \mathrm{O}_{3} ; \mathrm{O}, \mathrm{SiO}_{2}$.

The quantification accuracy can probably be improved by choosing an iron oxide for the Fe standardization (in the present case, fayalite $\left(\mathrm{Fe}_{2} \mathrm{SiO}_{4}\right)$ was used, and it may be that the ZAF correction did not work perfectly due to the relatively large density difference between the target and standard samples).

Precise oxygen quantification with the use of an osmium coating may also be effective for the estimation of the hydrogen (water) content in hydrous minerals. In the conventional case, the water content can be estimated roughly from the deficit of the total $\mathrm{wt} \%$ (sum of all the oxides subtracted from $100 \%$ ), assuming that the deficit is wholly attributed to the $\mathrm{H}_{2} \mathrm{O}$ component. In contrast, with the present method, the hydrogen content can be estimated solely from the deficit, since all the oxygen contained is directly quantified. Table 4 shows the quantification results for osmium-coated natural antigorite, $(\mathrm{Mg}, \mathrm{Fe}, \mathrm{Al})_{6} \mathrm{Si}_{4} \mathrm{O}_{10}(\mathrm{OH})_{8}$, as an example. The hydrogen concentration estimated from the deficit of the total $\mathrm{wt} \%$ is nearly equivalent to the stoichiometric value, although the standard deviation of the total is somewhat 

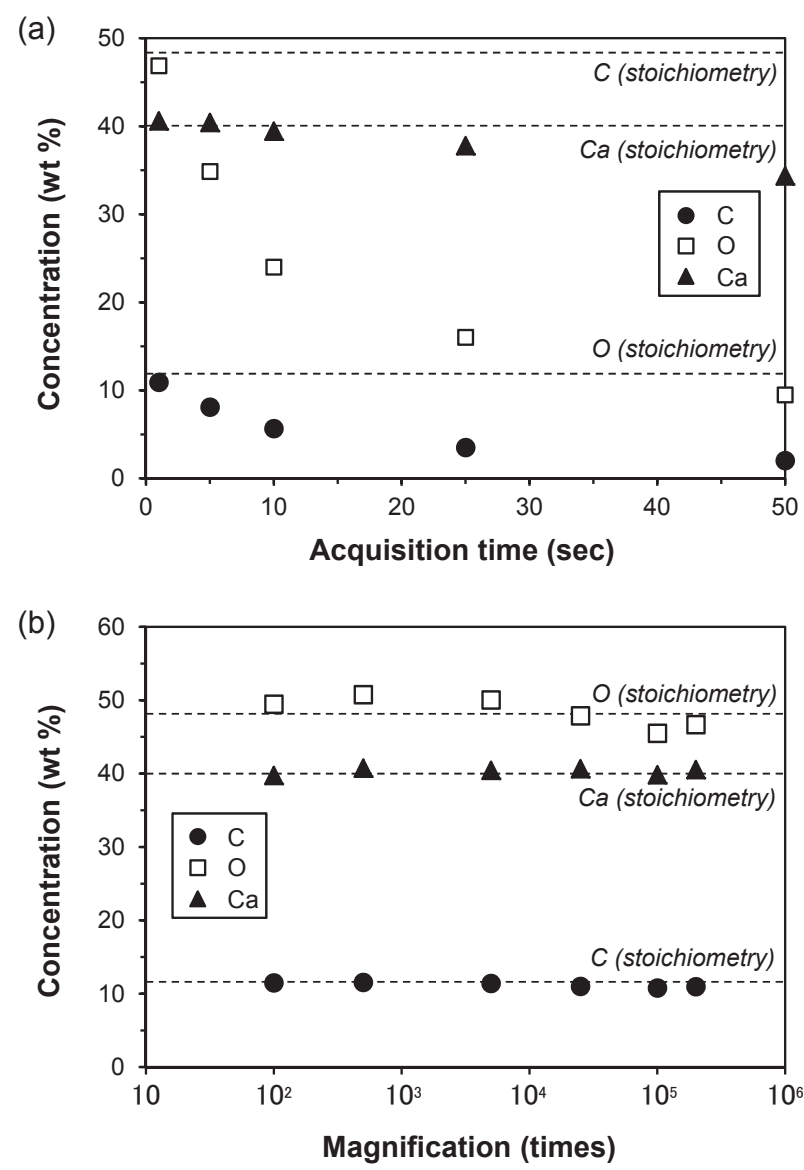

Figure 2. (a) Variation of the quantification results for $\mathrm{CaCO}_{3}$ at different acquisition times used for 'point analysis'. (b) Relationship between SEM magnifications used for 'area analysis' and quantification results at a fixed acquisition time (20 s). The magnifications used were $\times 100, \times 500, \times 5000, \times 25000$, $\times 100000$, and $\times 200000$, where the sizes of the areas scanned during analysis were approximately $750,150,15,3,0.8$, and $0.4 \mu \mathrm{m}^{2}$, respectively.

larger than in the case of anhydrous minerals (see Tables 1-3), which might be due to the high sensitivity of antigorite to electron-beam damage. The present method may be more helpful in estimating the amount of molecular water $\left(n \mathrm{H}_{2} \mathrm{O}\right)$ in hydrous minerals, particularly when describing the chemical composition of previously unknown species, since it is independent of the assumption of the bulk stoichiometry.

We next attempted the quantification of carbon, which is not practically feasible when using carbon surface coatings. Figure 2a shows the quantification results for osmium-coated natural calcite, $\mathrm{CaCO}_{3}$, from EDS spectra collected at different acquisition times. Note that the concentrations of all three elements (particularly $\mathrm{C}$ and $\mathrm{O}$ ) decrease drastically with the increase in acquisition time, suggesting specimen damage and element loss caused by the electron beam. In fact, the points irradiated with the electron beam for longer durations were found to be charged after the measurements because of the beam damage. Therefore, we investigated the "area analysis" technique, in which the electron beam is continuously scanned over a given square, for the same sample. Figure $2 \mathrm{~b}$ shows the relationship between the concentration of each element and the SEM magnification used for the area analysis (from the entire displayed area). The quantification values are nearly comparable to the stoichiometric ones, even at very high magnifications, suggesting that the osmium coating is effective for carbon quantification in carbonates, as long as the target area is not subjected to beam damage. Similarly, we found this technique to be effective in the quantification of carbon and nitrogen in the organic compound melamine, $\mathrm{C}_{3} \mathrm{~N}_{6} \mathrm{H}_{6}$, as reported in our earlier paper (Kojima and Ohfuji, 2013). Gold coating is probably not appropriate for the precise quantification of carbon, since the main peak of the $\mathrm{N}$ fluorescent X-rays of gold overlaps with the carbon $\mathrm{K}^{-}$ line located at $0.277 \mathrm{keV}$, as mentioned in the paper. It should, however, be noted that the accuracy of the EPMA quantification of such ultra-light elements is influenced by the choice of the matrix correction algorithm used for quantitative calculation. The XPP model (Pouchou and Picoir, 1991) employed in the analytical software programs (INCA and AZtec) used in Kojima and Ohfuji (2013) and the present study is not sufficiently optimized for the matrix correction for light elements. Therefore, although our empirical results show good reproducibility and acceptable validity for the quantification of carbon and nitrogen, the use of a better matrix correction model is required for the more accurate quantification of light elements, particularly at low concentrations.

Another benefit of osmium coating can be realized in elemental mapping analysis, which can visualize the distribution (presence or absence) of carbon in a sample. Stacking a number of frames in a mapping analysis can reveal the exact location of carbon, even at low concentration.

Furthermore, the $5 \mathrm{~nm}$ osmium coating used in the present EDS analysis was thin enough to enable the collection of electron backscattered diffraction (EBSD) patterns with acceptable quality, although a thinner coating provides better pattern quality (Fig. 3). Therefore, a user need only thinly coat a sample once before performing both EDS and EBSD analyses, and no extra time-consuming efforts such as re-polishing and/or re-coating are needed.

In our laboratory, we have prepared a series of standard minerals/materials coated with osmium and are using them (together with unknown samples to be analyzed) to check quantification accuracy and update the $\mathrm{X}^{-}$ 

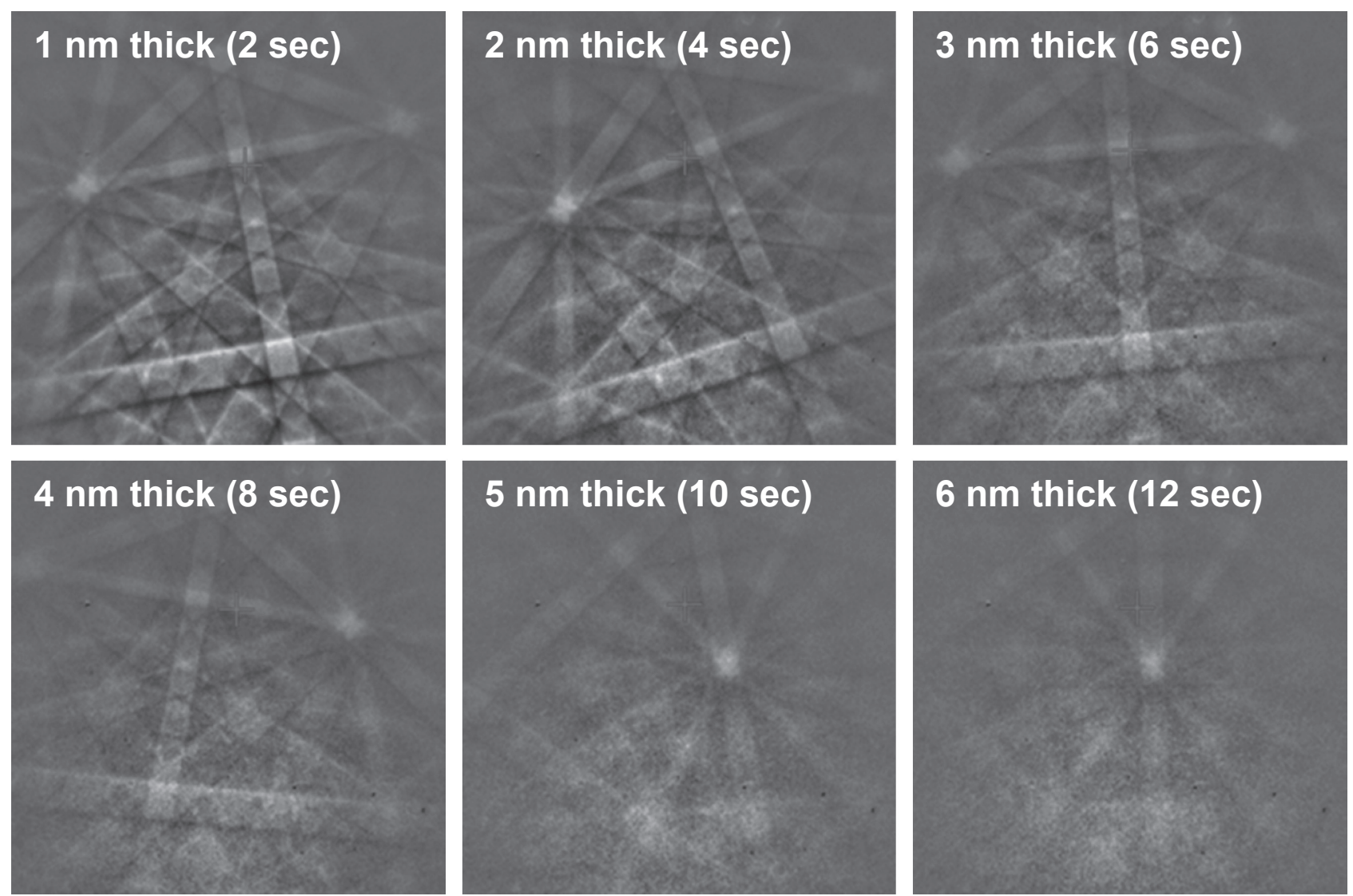

Figure 3. Variation of EBSD pattern quality as a function of the thickness of the osmium surface coating, as controlled by coating duration. EBSD patterns were obtained from the mirror-polished surface of a natural single-crystal diamond at a beam current of $5 \mathrm{nA}$ and an accelerating voltage of $15 \mathrm{kV}$.

ray standard profiles of each element on a routine basis. Although careful attention is needed when charging a new vial containing toxic $\mathrm{OsO}_{4}$ crystals as the gas source (typically required at intervals of 50-60 coatings), osmium coating provides a convenient and flexible alternative for sample preparation for EPMA and EBSD analysis.

\section{ACKNOWLEDGMENTS}

We thank Dr. Y. Kojima for his dedicated support in quantification data collection. This work was supported by JSPS KAKENHI Grant Number 26287138. The authors appreciate T. Irifune of Ehime University for his discussion and encouragement. We also thank Dr. Satoshi Utsunomiya (Associate Editor), Dr. Takenori Kato and an anonymous reviewer for their critical reviews and comments that helped to improve the present report.

\section{REFERENCES}

Akahori, H., Handa, M., Yoshida, H. and Kozuka, Y. (2000) Osmium-metal coating device using hollow-cathode plasma
CVD method. Journal of Electron Microscopy, 49, 735-744. Bastin, G.F. and Heijligers, H.J.M. (1991) Nonconductive specimens in the electron probe microanalyzer - a hitherto poorly discussed problem. In Electron probe quantitation (Heinrich, K.F.J. and Newbury, D.E. Eds.). pp. 400, Plenum Press, New York, 163-175.

Bizouard, H. and Charpentier, F. (1979) Essai d'analyse du carbone et de l'oxygéne dans les minéraux. Journal de Microscopie et de Spectroscope Électroniques, 4, 149-162.

Chantler, C.T. (1995) Theoretical form factor, attenuation and scattering tabulation for $Z=1-92$ from $E=1-10 \mathrm{eV}$ to $\mathrm{E}=0.4-$ 1.0 MeV. Journal of Physical and Chemical Reference Data, 24, 71-643.

Duncumb, P. and Melford, D.A. (1966) In X-ray optics and microanalysis (Castaing, R., Deschamps, P. and Philibert, J. Eds.). pp. 374, Hermann, Paris, 240-253.

Jercinovic, M. and Williams, M. (2005) Analytical perils (and progress) in electron microprobe trace element analysis applied to geochronology: Background acquisition, interferences, and beam irradiation effects. American Mineralogist, 90, 526-546.

Kato, T. (2007) Monte Carlo study of quantitative electron probe microanalysis of monazite with a coating film: Comparison of $25 \mathrm{~nm}$ carbon and $10 \mathrm{~nm}$ gold at $\mathrm{E}_{0}=15$ and $25 \mathrm{keV}$. Geostandards and Geoanalytical Research, 31, 89-94.

Kojima, Y. and Ohfuji, H. (2013) Structure and stability of carbon 
nitride under high pressure and high temperature up to 125 GPa and 3000 K. Diamond and Related Materials, 39, 1-7.

Love, G., Cox, M.G.C. and Scott, V.D. (1974) Electron probe microanalysis using oxygen x-rays: I. mass absorption coefficients. Journal of Physics D: Applied Physics, 7, 2131-2141.

Osawa, T. and Nozaka, Y. (1998) Scanning electron microscopic observation of the epidermal basement membrane with osmium conductive metal coating. Journal of Electron Microscopy, 47, 273-276.

Pouchou, J.L. and Pichoir, F. (1991) Quantitative analysis of homogeneous or stratified microvolumes applying the model "PAP". In Electron probe quantitation (Heinrich, K.F.J. and Newbury, D.E. Eds.). pp. 400, Plenum Press, New York, 3175.

Suzuki, E. (2002) High-resolution scanning electron microscopy of immunogold-labelled cells by the use of thin plasma coating of osmium. Journal of Microscopy, 208, 153-157.
Tanaka, A. (1994) Osmium conductive metal coating for SEM specimen using sublimated osmium tetroxide in negative glow discharge. Journal of Electron Microscopy, 43, 177-182.

Weisweiler, W. (1974) Elektronenstrahl-mikroanalytik elektrisch nichtleitender proben leichter elemente am beispiel von oxiden. Archiv für das Eisenhüttenwesen, 45, 287-294.

Willich, P. and Obertop, D. (1990) Quantitative EPMA of ultralight elements in non-conducting materials. In Proceedings of the $12^{\text {th }}$ International Congress on X-ray Optics and Microanalysis (Jasleńskam S. and Maksymowicz, J. Eds.). Academy of Mining Metallurgy, 100-103.

Manuscript received November 26, 2014

Manuscript accepted July 13, 2015

Manuscript handled by Satoshi Utsunomiya 